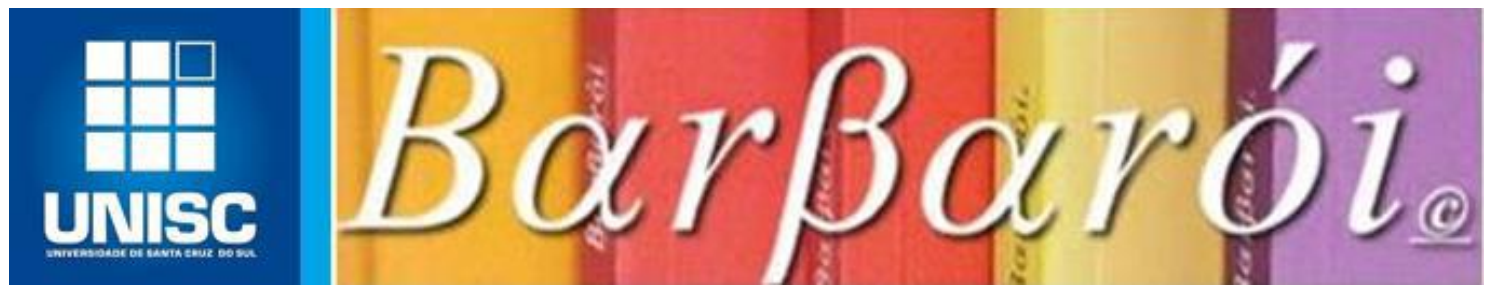

\title{
PARTICIPAÇÃO POLÍTICA JUVENIL: PRODUÇÃO DE SENTIDOS NO CONTEXTO DE OCUPAÇÕES DE UNIVERSIDADES
}

\section{DOI: http://dx.doi.org/10.17058/barbaroi.v1i53.12878}

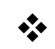 \\ Demyhellen Araújo Souza Aragão \\ Universidade de Pernambuco - UPE - Brasil \\ Érika de Sousa Mendonça \\ Universidade de Pernambuco - UPE - Brasil \\ Kerollayne Cavalcante Gominho \\ Universidade de Pernambuco - UPE - Brasil \\ Nathalia Regina Rodrigues Rocha de Santana \\ Universidade de Pernambuco - UPE - Brasil \\ $*$
}

\section{Resumo}

Os movimentos de Ocupação ocorridos no segundo semestre de 2016, no âmbito educacional brasileiro, evidenciaram um cenário em que estudantes passaram cerca de dois meses habitando instituições de ensino, em reivindicação de pautas e em manifestos de posicionamentos contrários à Proposta de Emenda Constitucional amplamente reconhecida como a PEC 241 (ou 55). Diante deste contexto adverso e suas manifestações de resistência, a pesquisa foi realizada sob a perspectiva epistemológica do Construcionismo Social e objetivou analisar sentidos de participação política construídos por jovens que vivenciaram o movimento de Ocupação em Universidades públicas. Para tanto, foram realizadas 20 entrevistas individuais, semiestruturadas, junto a 10 jovens estudantes da Universidade de Pernambuco e outros 10 da Universidade Federal Rural de Pernambuco, nos campi situados na cidade de Garanhuns-PE. Os dados construídos foram analisados por meio das práticas discursivas e produção de sentidos no cotidiano, que propõem analisar processos e modos de Subjetivação, tomando as discursividades como linguagem em ação. Como resultados, compreende-se que as Ocupações não atingiram suas principais reivindicações, porém as atividades de formação política empreendidas, a interação entre ocupantes e o convívio com dimensões contrárias àquelas por eles defendidas, promoveram vivências de participação política, visibilizadas através de diálogos e negociações cotidianas, de posicionamentos críticos e de implicações em movimentos que se deslocam do si mesmo em direção ao outro, promovendo implicações subjetivas políticas nos envolvidos.

Palavras-chave: Participação Política; Ocupação; Juventude. 


\section{Introdução}

O jovem como sujeito plural, em suas distintas formas de ser e se expressar, diante do cenário político e econômico contemporâneo e das exigências sociais que sobre ele recaem, inclusive no âmbito das políticas públicas e da produção de conhecimentos, faz eclodir o fenômeno das "juventudes". Estas, mais que uma geração, apresentam-se como categoria psicossocial de importância, dadas suas vivências e posicionamentos desnaturalizantes (ou mesmo de tradição e conservação) frente a contextos múltiplos: família, escola, trabalho, cidade, amizade, sexualidade ou, ainda, ante cenários de questionamento quanto a práticas reificadas em relação a gênero, raça, orientação sexual, religião e política, merecendo até mesmo discussões que busquem situar a presença do sujeito jovem em pesquisas que discutem juventudes, como refletem autores como Abramo e Branco (2005), Esteves e Abramovay (2007); Mayorga e Pinto (2012); Mendonça (2008; 2016) e Castro (2019).

Para entendermos como essa concepção passa a ser levada em consideração, é a partir do século XX que a juventude começa a ser problematizada e se provocam discussões nos campos das ciências e políticas públicas, pela oscilação percebida na literatura que aponta, por um lado, jovens como atores de mobilização de forças sociais, enquanto, do outro lado, os estudos os relacionam a contextos de delinquência e outros problemas sociais (CASSAB, 2011).

Assim é que a revisão bibliográfica do tema encontra destaque nas produções acadêmicas que relacionam a juventude a problemas sociais, tais como criminalidade, uso abusivo de drogas, apatia política, abandono escolar e desemprego, como denunciam Alvim (2003) e Pais (2005). Por outro lado, jovens também são apresentados na literatura especializada como sujeitos sociais de relevância na construção de seu tempo histórico, enquanto atores políticos que, coletivamente, produzem significados e alteram o seu espaço e são transformados por eles, assim como defendem Mellucci (1997); Dayrell (2007), Castro e Mattos (2009), Mendonça, Andrade e Holanda (2016). Seja pelo impacto social de suas escolhas, ou mesmo pelas denúncias da realidade em que vivem, através de engajamentos dinâmicos e inventivos, as juventudes também se posicionam no campo político (CORROCHANO, DOWBOR, JARDIM, 2018; Vieira, 2019).

Diante da multiplicidade de olhares lançados aos jovens, abraçamos a perspectiva da potência atribuída à participação política juvenil pois, de acordo com Mendonça (2016, p. 59):

Quando se trata da população jovem, essa participação parece tornar-se ainda mais importante, pois desse modo o jovem estará posicionado como agente de mudanças, assumindo responsabilidades e tomando para si projetos em que se empenhar.

Barbarói, Santa Cruz do Sul, n.53, p.<26-48>, jan./jun. 2019 
No Brasil, em junho de 2013, 12 capitais brasileiras foram tomadas por manifestações populares que reuniram mais de um milhão de pessoas, lutando por pautas múltiplas desencadeadas pelo aumento da passagem de ônibus, mas logo se ampliando a questionamentos políticos, de uso de dinheiro público e de corrupção (GOHN, 2014). Este movimento ficou conhecido como "Jornadas de Junho"1. O vivido neste contexto nos fez relembrar três grandes momentos da história nacional: nos anos 1960, nas greves e paralizações antes ao golpe militar de 1964, e ainda as passeatas estudantis de 1968; em 1984, no movimento Diretas Já, no período do regime militar, com a luta pelo retorno à democracia; e em 1992, o impeachment do ex-presidente Collor de Melo (GOHN, 2014).

O contexto de efervescência política brasileira teve sua culminância, porém, em 2016, quando no dia 31 de agosto se deu o golpe/impeachment da então Presidenta Dilma Rousseff ${ }^{2}$, fato que gerou polêmicas, lutas e dividiu opiniões em relação à legitimidade do processo de cassação política da Chefe de Estado. Assim, veio à tona a rejeição ao poder atribuído ao vice-presidente Michel Temer - que assumiu a presidência da república - gerando descontentamento popular, bem como a suas políticas de governo e cortes fiscais anunciados, especialmente no contexto da educação. Ainda, a rejeição se colocou diante de projetos de lei que também atingiam diretamente o âmbito educacional. Nesse interim, em outubro de 2016, foram deflagrados movimentos de Ocupação, quando mais de mil instituições de ensino ${ }^{3}$ vieram a ser ocupadas por estudantes, em âmbito nacional.

Esta parcela da população, em sua maioria jovens, percebia-se, naquele cenário, sob a ameaça de retrocesso em relação ao acesso à educação de nível superior, bem como sua manutenção nesses espaços. Desde 2000 evidenciaram-se dados que informavam a ampliação de acesso de jovens ao ensino superior, passando de $9,1 \%$ para $18,7 \%$ e, nas regiões Norte e Nordeste, chegaram a triplicar estes números (CORBUCCI, 2014). Destacou-se, no período, também, o fortalecimento e ampliação de investimentos em projetos que garantem ou facilitam a entrada e manutenção de estudantes em cursos superiores, como o Fies (Fundo de

\footnotetext{
1 Disponível em: <https://www.nexojornal.com.br/expresso/2017/06/17/O-que-foram-afinal-as-Jornadas-deJunho-de-2013.-E-no-que-elas-deram> Acesso em: 31 mai. 2018

2 Disponível em: <https://www12.senado.leg.br/noticias/materias/2016/12/28/impeachment-de-dilma-rousseffmarca-ano-de-2016-no-congresso-e-no-brasil> Acesso em: 09 set. 2019

3 Disponível em: <https://brasil.elpais.com/brasil/2016/10/24/politica/1477327658_698523.html> Acesso em: 10 abr. 2018
} 
Financiamento Estudantil), ProUni (Programa Universidade para Todos), SISU (Sistema de Seleção Unificada) e Programa de Cotas (MARQUES, XIMENES, UGINO, 2018).

O movimento Ocupações surge, então, em resposta a um cenário de decisões políticas que afetaria o país, num claro manifesto de rejeição frente ao Projeto de Emenda Constitucional (PEC) 241 ou 55, que previa o congelamento dos gastos públicos, principalmente nas áreas de educação e de saúde e a reforma do ensino médio. Nos casos específicos das Universidades pesquisadas havia, ainda, em suas pautas, reivindicações de políticas locais, como a implantação de casas do estudante, restaurantes universitários, estrutura física das salas de aula e laboratórios; apoiavam, ainda, a conquista de políticas próprias à categoria de professores, como a implantação do regime de dedicação exclusiva e a reposição salarial. Movimentavam-se, os jovens, nesse sentido, de modo ativo e coletivo, transformando queixas em ações.

Entendíamos, assim, pelo vivido nos corredores da própria Universidade, que estávamos diante de jovens que se descobriam ou se expressavam, naquele contexto específico, como sujeitos atuantes e criticamente posicionados. Estávamos diante de uma vivência inédita que reunia jovens estudantes, num movimento político de resistência ao instituído, tal como descrito por Mendonça (2019, p. 444): “Assim, entendemos a aceitação sem questionamento ou reflexão crítica como o assujeitamento e o seu oposto estaria na elaboração de manobras, de estratégias, de subterfúgios àquilo que é imposto ou esperado, sendo identificado como resistência".

Neste âmbito, nos debruçamos a compreender o processo de politização ali experienciado e nos indagamos: como esses jovens estudantes vivenciaram os movimentos de Ocupação? Que sentidos construíram sobre essa experiência e sobre o sujeito político? Esses questionamentos nos impulsionaram a pesquisar a produção de sentidos, considerando desde a motivação à adesão e permanência dos estudantes no movimento.

Diante do exposto, essa pesquisa objetivou analisar sentidos de participação política construídos por jovens que vivenciaram o movimento de ocupação em Universidades públicas em um município no interior de Pernambuco. Para tanto, entendemos que o sentido é construído socialmente: “os processos de produção de sentidos implicam existência de interlocutores variados cujas vozes se fazem presentes. As práticas discursivas estão sempre atravessadas por vozes; são endereçadas e, portanto, supõem interlocutores.” (SPINK, 2010, p.35). Foi nesse diálogo que investigamos e buscamos compreender formas de conceber 
política para esses jovens e como a ocupação pôde contribuir na trajetória de vida dos ocupantes.

\section{Metodologia}

A pesquisa desenvolvida teve cunho qualitativo, construída e analisada pelo viés do Construcionismo Social, que possibilita ao estudo um modo de se portar desreificante, desnaturalizante, desessencializador, radicalizando a natureza social do mundo vivido e a historicidade das práticas (SPINK, 2010). Dessa maneira, "ocupa-se principalmente de explicar os processos pelos quais as pessoas descrevem, explicam, ou, de alguma forma, dão conta do mundo em que vivem (incluindo-se a si mesmas)" (GERGEN, 2009, p.301).

Para a construção dos dados, foram realizadas entrevistas individuais semiestruturadas com jovens de diferentes pertencimentos, a saber: sexo, situação socioeconômica, participação em espaços de formação continuada (ex. projetos sociais) ou de formação política (ex. movimento estudantil). Desse modo, visamos garantir um conjunto variado de informantes para possibilitar discussões e multiplicidades de olhares, no que diz respeito aos sentidos atribuídos às experiências de participação política juvenil, no contexto das Ocupações das Universidades.

Diante disso, foram entrevistados 20 jovens, tendo 10 deles participado efetivamente do movimento de Ocupação na Universidade de Pernambuco (UPE) - Campus Garanhuns e outros 10, integrantes da Universidade Federal Rural de Pernambuco (Também denominada UAG - Unidade Acadêmica de Garanhuns). Todos contemplaram a faixa etária entre 18 e 29 anos, seguindo a orientação de "sujeitos jovens" de acordo com o Conselho Nacional de Juventude (CONJUVE). No tocante às entrevistas, aconteceram entre os períodos de seis meses até 1 ano após o término das Ocupações. Esse distanciamento temporal foi importante, pois permitiu já uma série de reflexões acerca do vivido e das repercussões do movimento.

Ainda há que se realçar o método de escolha dos sujeitos envolvidos na pesquisa. $\mathrm{Na}$ UPE, sendo esta a instituição de ensino de que participam as pesquisadoras, o contato foi facilitado por conhecermos os estudantes que haviam participado ativamente do movimento, favorecendo o acesso e o convite para que fossem informantes da pesquisa. Já na UAG, houve dificuldades em estabelecer contato com os ocupantes. Havia nítida e declarada insegurança dos estudantes em participar da pesquisa, uma vez que os movimentos de ocupação na região haviam sido criminalizados e, nesta unidade acadêmica, havia ameaças de processos jurídicos e alguns dos estudantes sofriam retaliações por prejuízos na formação/conclusão do curso. A 
negativa dos estudantes era clara, quando se anunciava o tema da pesquisa, e um dos ocupantes que se disponibilizou a ser entrevistado evidenciou tal situação.

Diante de tal contexto, foi adotada a técnica de amostragem em bola de neve, que de acordo com Vinuto (2014, p. 203) "é uma forma de amostra não probabilística, que utiliza cadeias de referência. Ou seja, a partir desse tipo específico de amostragem não é possível determinar a probabilidade de seleção de cada participante na pesquisa(...)". Trata-se de um método viável a ser aplicado em grupos em que se percebem dificuldades de acesso. Inicialmente lança-se mão de um informante-chave, que vai identificar outras pessoas que tenham o perfil para a pesquisa (VINUTO, 2014). Nesse caso, traçamos critérios de inclusão de informantes: ter participado ativamente da Ocupação, ter idade na faixa-etária prevista de juventudes e ser, na época das ocupações, estudante matriculado na instituição de ensino.

No que concerne aos cuidados éticos, os jovens participaram voluntariamente e estavam cientes sobre o tema de pesquisa, sendo respeitado o desejo e disposição dos sujeitos envolvidos. A partir disso, foram assinados os documentos de Termo de Consentimento Livre e Esclarecido (TCLE) e Termo de Confidencialidade, atendendo à resolução 466/2012 do CNS/CONEPE, que diz que o indivíduo objeto da pesquisa ou seu representante legal deverá receber uma explicação clara e completa, em linguagem simples e acessível, sobre a pesquisa no qual está sendo objeto de estudo. Afirma-se também, neste documento, o direito do informante em desistir de sua participação a qualquer momento. Também cuidados éticos mais subjetivos foram nossos guias, estando atentas a possíveis desconfortos manifestos pelos jovens que, afinal, pareceram estar confortáveis com a situação de pesquisa e com o tema em tela.

Para uma melhor análise das práticas discursivas dos participantes, foram feitas gravações das entrevistas, sendo devidamente autorizadas pelos sujeitos envolvidos. $\mathrm{Na}$ sequência, passamos ao processo de transcrição literal, seguido de agrupamentos em tópicos de discussão, que serão trabalhados no decorrer do artigo.

\section{Resultados e discussões}

O movimento de Ocupação de Instituições de Ensino Superior no contexto brasileiro, que se deu a partir de outubro de 2016, foi vivido também por estudantes do interior do estado de Pernambuco. Porém suas raízes se estabeleceram nas Ocupações que começaram a ser vivenciadas no segundo semestre de 2015, com os estudantes secundaristas do estado de São Paulo, em resposta à reorganização escolar proposta pelo governo de Geraldo Alckmin, que 
previa o fechamento de 94 escolas públicas no Estado. Na ocasião, foram ocupadas mais de 200 escolas em todo o estado, em combate ao sucateamento da educação pública. ${ }^{4}$

Houve apoio popular ao movimento, de modo geral, sendo legitimado pelo Tribunal de Justiça de São Paulo e nomeado de "Primavera Secundarista". 5 A partir desse movimento, outros estados brasileiros começaram a integrar e formar redes de apoio, passando a vivenciar as ocupações, incluindo-se as unidades de ensino superior. As reivindicações incluíam uma rejeição à reforma do ensino médio e a negativa à PEC (Projeto de Emenda Constitucional) 241 ou 55. A pauta da PEC, embora debatida, não conseguiu produzir os efeitos de impedimento de aprovação pleiteados, tendo sido aprovada no senado no dia 13 de dezembro de 2016 e promulgada no dia $15^{6}$. Mas o movimento se manteve forte em denunciar a insatisfação dos estudantes e em buscar modos de resistir e lutar e teve efeitos de formação e socialização política, como nos fizeram refletir alguns dos participantes da pesquisa.

A análise dos dados obtidos na pesquisa foi refletida a partir de três tópicos de discussão, onde buscamos compreender os movimentos de Ocupação vivenciados pelos estudantes de ambas as instituições, historiando a chegada, a vivência e a saída do movimento, e suas reverberações e sentidos produzidos.

\section{O que levou os jovens à participação: consciência política e seus desdobramentos}

Segundo Gohn (2011) os movimentos sociais conseguem produzir um diagnóstico da realidade social. A partir disso, passam a construir propostas, atuam em redes, se articulam em ações coletivas de resistência à exclusão e lutam para inclusão social, desenvolvendo o empowerment dos atores da sociedade para se organizarem como sujeitos sociais na atuação dessas redes.

Partindo dessa definição, pode-se destacar que a cena política em que se instaura o movimento de ocupação parte da análise dos jovens desse contexto em que estavam inseridos, refletindo-se, também, as repercussões dos projetos de governo para a sociedade. Isso se evidencia nas práticas discursivas de alguns dos participantes, quando questionados sobre suas motivações à entrada no movimento:

\footnotetext{
4 Ver o documentário: ACABOU A PAZ, Isto aqui vai virar o Chile! Escolas Ocupadas em SP. Direção, Produção e Roteiro: Carlos Pronzato; Edição: Lucas Duarte de Souza. 60" 6'. Disponível em: $<$ https://www.youtube.com/watch?v=LK9Ri2prfNw\&t=550s> Acesso em: 10/04/2018

${ }^{5}$ Acessar a página da UBES- União Brasileira dos Estudantes Secundaristas. <http://ubes.org.br/?s=ocupações>

6 Consultar: https://www.cartacapital.com.br/politica/pec-que-congela-gastos-sociais-e-aprovada-em-segundoturno-no-senado
} 
Foi mediante a uma análise da conjuntura política e social e econômica, também, né?! Que é um efeito dominó, que tá, está passando com a gente naquele momento (Aloísio $\left.{ }^{7}, \mathrm{UAG}\right)$.

O que me levou foi pensar em um todo, não só em mim, é... não só tá no meu nível de conforto. Mas no momento, o que eu pensava era numa luta coletiva, a gente não poderia deixar as coisas andarem pelos caminho que tavam indo, que a gente tinha que fazer alguma intervenção (Iracema, UPE).

No geral um posicionamento político, de ficar incomodada com algumas coisas que estavam acontecendo no país, e especificamente falando a respeito da PEC, né? (Gal, UAG)

Desse modo, podemos realçar que a iniciativa dos estudantes em se unirem para ocupar espaços públicos, como suas instituições de ensino, pode ser compreendida como ato de empoderamento individual e coletivo. Faz-se necessário, para melhor compreensão, uma análise dessa categoria de estudo no âmbito das ciências sociais.

Historicamente Baquero (2012) traz que esse neologismo - empoderamento (ou empowerment) - surge tradicionalmente na reforma protestante, mas ganha notoriedade na atualidade por conta dos movimentos emancipatórios e de garantia da cidadania - movimento dos negros, das mulheres, entre outros. Seus principais significados remetem a poder, a obtenção e alargamento das forças pessoais ou grupais, em níveis intrapsíquicos, comportamentais, auto emancipação, análise das potencialidades de si. Remete também à possibilidade de empoderamento comunitário, organizacional, modos de se conectar com outros e unir forças para potencializar aquilo que se espera executar, visando o interesse comum.

Nesse sentido, o movimento dos secundaristas teria fortalecido os estudantes universitários a se levantarem em protesto, pressupondo empoderamento em seus diferentes níveis. A discursividade de Isabel (UAG), evidencia tal encadeamento de forças:

(...) começou em algumas escolas e saiu eclodindo, que é o exemplo que arrasta né não? aí fala! fala! fala! fala! falar todo mundo fala, mas o exemplo arrasta, a gente se sentiu motivado por outros estudantes que fizeram isso, porque a gente não foi primeiro não, a gente não foi vanguarda, outros estudantes fizeram isso, a gente: $\mathrm{P}^{*}$ é possível! Bora fazer? Aí isso nos motivou (...)

Euclides (UPE) nos conta como foi sua tomada de decisão para adesão ao movimento de Ocupação: "Eu pensava em voltar pra casa. Mas quando eu participei da reunião dessa noite e eu vi, eu fiquei assim: Poxa, véi! Eles tão aqui por mim, por mim!”

\footnotetext{
${ }^{7}$ Serão utilizados nomes fictícios para manter o sigilo da identidade dos participantes da pesquisa. Barbarói, Santa Cruz do Sul, n.53, p.<26-48>,jan./jun. 2019
} 
Melucci (1997), refletindo sobre movimentos sociais, destaca a dimensão do sentir-se convocado e afirma: "Os jovens se mobilizam para retomar o controle sobre suas próprias ações, exigindo o direito de definirem a si mesmos contra os critérios de identificação impostos de fora, contra sistemas de regulação que penetram na área da 'natureza interna ${ }^{-8}$. (p. 13). Dessa forma, entendemos que o processo de se mobilizar passa pela retomada, ou mesmo pela possibilidade de ter autonomia, quando o sujeito jovem aparece coletivamente e reivindica o espaço das juventudes serem criadoras de suas ações.

Nas duas Universidades aconteceram assembleias que precederam a deflagração e a organização do movimento de Ocupação e discutiram a situação político-econômica brasileira. Para alguns dos entrevistados, antes das reuniões e debates acontecerem, já havia indicativos e um plano para a Ocupação, assim somariam com aqueles que já estavam lutando em outras localidades. Para outros, o sentimento gerado na assembleia deu forças para ocupar junto aos seus colegas. Num ou noutro caso, desde o passo da tomada de decisão se percebe a consciência política de estar em conjunto reivindicando seus direitos como cidadãos.

Jorge (UPE) destaca como se sentiu na assembleia e como decidiu ocupar:

(...) a assembleia noturna, quando teve ela eu senti um impacto muito grande, assim... foi muito impactante para mim, escutar algumas coisas de algumas pessoas que queria ocupar e aí eu acho que juntou as duas coisas: tanto essas questões políticas que foram acontecendo, não só em relação a Garanhuns, tinham algumas eu acompanhava poucas, mas acompanhava algumas. Mas a nível de Brasil mesmo e aí essas discussões e o sentimento que eu tive ali naquele momento, foi que fez eu realmente vir para ocupar (...)

Isabel (UAG) narra sua experiência de organizar a reunião com os estudantes:

(...) a gente, como representação estudantil, aquele momento, a gente tava vivendo bastante retrocesso, um atrás do outro, aí a gente organizou as assembleias de estudantes e nesse dia dessa assembleia a gente decidiu que íamos ocupar no dia seguinte a Universidade pela manhã, é... os motivos eram justamente esses: contra os retrocessos e o fato de tá vendo esse fenômeno nacionalmente e isso impulsionou e a gente se sentiu mais apoiado (...)

A partir disso, os estudantes precisavam se articular e conduzir o movimento. Dessa maneira, investir na formação política e no diálogo como forma de construção das práticas dentro da Universidade, surge a partir da decisão de que haveria Ocupação, mesmo considerando-se as possibilidades de conflitos e opiniões contrárias. Segundo Carrano (2012) isso acontece justamente pelo processo de conscientização política da juventude:

\footnotetext{
${ }^{8}$ Aspas do autor.
}

Barbarói, Santa Cruz do Sul, n.53, p.<26-48>,jan./jun. 2019 
A possibilidade de formação de uma dada consciência jovem seria a expressão de conflitos e tensões que se desenvolvem no âmbito do sistema e que encontrariam nos movimentos de juventude seus canais de extravasamento. Aos jovens caberia uma nova elaboração, não institucionalizada, da conjuntura crítica por intermédio de ações de enfrentamento à ordem estabelecida (...) (p. 91).

Partindo desse pressuposto, cada ocupação de forma particular conduziu suas atividades, vivenciou distintas dificuldades, porém o arranjo se torna semelhante entre os movimentos por terem o apelo histórico que urge para as juventudes e reivindica a força da coletividade, por vivenciarem dias em estreita convivência, por exercitarem a tomada de decisões, apesar da divergência de opiniões, mergulhando numa formação política de maneira ampliada, na dialogia e no dissenso com aqueles que não concordavam, ou mesmo nos desafios diário do convívio com o outro.

Jorge (UPE) narra as dificuldades por ele percebidas no início das ocupações, já que era algo inaugural para aquela Universidade, que até então não havia vivenciado nenhum tipo de greve ou movimentação daquele porte:

\footnotetext{
Porque ao mesmo tempo que a gente tinha um sentido político, a gente tinha uma reivindicação, tanto eu como todo a maioria do pessoal que tava, gente muito novo, então assim... em algum momento a gente foi percebendo que tava saindo do foco, que a gente tava disperso demais, estava pouco fundamentado naquilo que tava defendendo ou naquilo que pensava, mas isso acho que mais no início mesmo da ocupação, de que apesar de a gente saber o sentido, não era tão palpável (...).
}

Gohn (2008) assegura que: “O movimento social, como um sujeito social coletivo, não pode ser pensado fora de seu contexto histórico e conjuntural. As identidades são móveis, variam segundo a conjuntura. Há um processo de socialização da identidade que vai sendo construída" (p. 444). Sendo assim, o movimento de ocupação foi diariamente sendo erguido através dos ocupantes, foi sendo produzido e ganhando formas, e por isso nos questionamos: o que é participar politicamente para esses jovens?

\section{Experimentação da Participação Política Juvenil num contexto micropolítico: as Ocupações}

Ocupamos! E agora? O impacto inicial se foi e os ocupantes começaram a agir. Nas duas Universidades os estudantes se organizaram em comissões que cumpririam determinada tarefa: seja limpeza, alimentação, atividades de formação (por exemplo: as palestras, rodas de conversa, cine debates, oficinas de arte, vivências culturais), seja panfletagem nas ruas, junto à sociedade, numa tentativa de expandir o movimento e levar conhecimento a todos, ou ainda nos corredores das suas Universidade, atuando junto à comunidade acadêmica que não aderiu 
ao movimento. Os ocupantes foram unânimes em afirmar que a liderança era compartilhada, assim como as responsabilidades.

Essa descentralização do poder e a atribuição de papeis centrais às forças coletivas, remete ao que Mouffe (2005) traz sobre a constituição e entendimento do poder nas sociedades democráticas:

Compreender a natureza constitutiva do poder implica abandonar o ideal de uma sociedade democrática como a realização de perfeitas harmonias ou transparência. $\mathrm{O}$ caráter democrático de uma sociedade só pode ser dado na hipótese em que nenhum ator social limitado possa atribuir-se a representação da totalidade ou pretenda ter controle absoluto sobre a sua fundação (p. 19).

Diante disso, ao incluirmos no roteiro de entrevista questionamentos sobre as concepções de democracia para os jovens, e se a experiência nas ocupações havia sido democrática, percebemos que para os sujeitos desse estudo o próprio direito de participar das ocupações advinham do regime democrático, mesmo com as distorções e tantos outros aspectos entendidos por eles como desafios dessa convivência.

O termo democracia vem do grego e é composto pelas palavras demos, que quer dizer povo e kratein, que significa reinar. Nesse sentido, democracia em tradução literal seria reinado popular ou reinado do povo (BECKER, RAVELOSON, 2011, p. 5). De acordo com os jovens ocupantes, democracia é:

(...) ideia política, que eu acho... as pessoas veem muito distorcidamente, mas que eu vejo como uma forma de você, de uma maioria pensar e de uma minoria pensar também" (Euclides, UPE).

(...) tem uma frase que fala e eu fico muito ambíguo, é, se concordo ou não, que democracia é a ditadura da maioria, que fala muito isso, e eu fico muito, muito pensando. Acho que não tem como a gente ser unânime, em nada, porque são muitas pessoas, são muitas cabeças, muitas ideias... então não tem como você abarcar tudo (José, UPE).

(...) democracia é uma ferramenta para que possamos conseguir atingir objetivos que beneficiem uma maioria, que não foquem apenas em uma pessoa ou o desejo próprio de alguém, mas que tente atingir o máximo de pessoas possíveis, o máximo de interesses das pessoas (Milton, UAG).

“(...) é as massas, é o diálogo é a conversação, é saber em quem votar, é saber quem escolher, é fiscalizar (...)” (Aloízio, UAG).

Observamos que na UPE, onde a ocupação foi aprovada por uma minoria, que se instalou no espaço público e se implicou no movimento entre uma aula e outra, entrando em desacordos e discussões com colegas que eram contrários aos seus argumentos (ali, maioria), professores insatisfeitos com a "teimosia e audácia" daqueles alunos (SIC), deixou abertas as 
portas da Universidade. Fortaleceu a ideia de voz às minorias como uma forma de assegurar a experiência de democracia e a concepção que formularam sobre esse regime. Tratava-se de uma minoria lutando por direitos e garantias que beneficiariam à maioria.

Isso se diferencia quando passamos a analisar a UAG que, para ocupar, fechou dois prédios e, associando-se à greve assumida por professores e técnicos administrativos, conseguiu apoio para o movimento. Certamente o movimento não ficou isento de conflitos e desacordos, incluindo os próprios colegas que formavam um coletivo contrário, e ainda entre eles mesmos, os companheiros de luta, os desentendimentos estiveram presentes. Mas o modo como pensam a democracia se instala na legitimidade da maioria como premissa básica. Essas divergências de ideias não se constituíram como impossibilidades de diálogos entre os movimentos, mas diz do foco de visão que se estabelece em consonância com a realidade em que vivem e, nesse caso, no movimento em que ocupam.

Mouffe (2003, p. 19) afirma que:

Tal pluralismo está ancorado no reconhecimento da multiplicidade de cada um e das posições contraditórias a que esta multiplicidade subjaz. Sua aceitação do outro não consiste meramente em tolerar as diferenças, mas em celebrá-las positivamente porque admite que, sem alteridade e o outro, nenhuma identidade poderia se afirmar.

Nesse sentido, os conflitos são entendidos como agonísticos, não anulam a ação do outro, mas permanecem diferentes, dando lugar à diversidade de opiniões, sentimentos e se afirmando um e outro em suas possibilidades coletivas. Para expandir essa reflexão, vamos analisar as relações entre os atores que estavam nas Universidades, a sociedade e a influência midiática. Alguns dos jovens participantes do estudo refletiram, por exemplo, sobre os desafios encontrados na convivência entre os próprios ocupantes:

Internamente, o convívio com humanos já é complicado por si, junta uma galera que nunca esteve junta, que o ideal era o mesmo, lutar contra a PEC, mas que tem visões de mundo diferente, de crenças diferentes, costumes diferentes e aí de vez em quando, claro, tinha lá seus embates (...) (Gal, UAG).

Os enfrentamentos e tensionamentos vivenciados no contexto das Ocupações, no caso dos estudantes da UPE, foram intensificados pelo fato de serem uma minoria e, principalmente, por estarem em meio ao funcionamento da instituição que contava com aulas regulares, dos cursos que não fizeram parte do movimento e lidando com posições contrárias:

A gente recebeu cuspida em barraca, as pessoas tavam dormindo e chutavam as barracas de propósito ou então, nós escutávamos piadinhas de, quando passava pelo corredor, não só do corpo discente mas do corpo docente também! Eu escutava horrores de alguns professores, chamando claramente de vagabundo, essas coisas assim. E era uma coisa que tipo assim, pesava! (José, UPE). 
Situações de risco também foram vividas na UAG. Uma situação destacada esteve na qualidade das doações recebidas: "Chegaram a entregar aqui água contaminada" (Milton, UAG).

O movimento era legítimo e é preciso refletir que não apenas as diferenças, mas também os embates estão presentes em sociedades democráticas. Mouffe $(2003 ; 2005)$ afirma que a ideia de consenso está relacionada ao conflito, pois não tem como se estabelecer na democracia pluralista uma decisão favorável a uma hegemonia, mesmo que temporária, sendo preciso favorecer o dissenso para que tenhamos um modo de sobrevivência da democracia a partir das identidades coletivas, que sejam posturas diferentes, e oportunizando para que possamos estar em consonância com a realidade, mas que sejamos adversários ao invés de inimigos. Ser adversário reflete a manifestação de uma ética-política alinhada no respeito ao posicionamento contrário, pois tem lugar nas decisões conjuntas. Para a autora, a violência tende a ser diluída com essa possibilidade de espaço à diversidade. Isso aconteceu quando ocupantes foram ameaçados, mas ao permitir a expressão e dar oportunidade ao diálogo, foi possível mudar posturas e nesse contexto foi motivo de resistência dos Ocupantes.

Ainda abordando os conflitos, durante o movimento, no início do mês de novembro daquele ano, seriam aplicadas as provas do Exame Nacional do Ensino Médio (ENEM) em todo o território brasileiro. Mas as instituições de ensinos estavam ocupadas, o que ocasionou a prorrogação dos dias de aplicação do exame em algumas escolas e Universidades que sediariam ${ }^{9}$, consequentemente adiando para alguns estudantes a possibilidade de fazer as provas. A partir disso a mídia, que já vinha noticiando de maneira "manipulada" as ocupações, passou a "distorcer" (sic) os motivos da continuidade e resistência dos ocupantes.

Como reitera Silva (2008, p. 05):

A mídia, de maneira geral, usa estereótipos para tratar os temas relacionados às
minorias no Brasil. Negros, movimentos sociais, mulheres e homossexuais são
frequentemente vítimas de textos jornalísticos preconceituosos. Com a juventude
isso não é diferente.

Em resposta a isso os participantes do movimento da UPE recusaram entrevistas, buscaram a população para mostrar que estavam lutando por uma educação de qualidade a longo prazo e não haveria como estarem contra os estudantes pré-universitários. Inclusive na UAG realizaram um "aulão" para os alunos que fariam as provas do Enem (Exame Nacional do Ensino Médio), articulando a sociedade com as Ocupações, indo à feira panfletar e ofertar

\footnotetext{
${ }^{9}$ Consultar: https://g1.globo.com/educacao/enem/2016/noticia/enem-2016-confira-lista-das-escolas-afetadaspelo-adiamento.ghtml Acesso em 08/03/2018.
}

Barbarói, Santa Cruz do Sul, n.53, p.<26-48>,jan./jun. 2019 
espaços de discussão na Universidade, que afinal é pública. Na UPE, além das panfletagens na cidade, foram desenvolvidas ações sociais de distribuição de alimentos para pessoas carentes. Houve, também, manifestações nas ruas, com participação conjunta das duas Universidades.

Essas atividades "fora dos muros" (sic) deram força ao movimento e construíram sentidos de participação política que se referem a investimentos em micro-ações cotidianas na direção da transformação social de realidades, à desnaturalização do que está instituído e gera segregação, a um olhar e um movimento na direção do que é coletivo.

\section{Participação Política durante a Ocupação e no cenário atual brasileiro: novos (ou ampliados) modos de participação}

Para Castro (2008, p. 254) "Entender a si mesmo como parte de um todo maior - uma nação por exemplo - requer uma lenta transformação subjetiva que redimensiona o sentido de lugar e de inserção do jovem". Foi a partir dessa autora que compreendemos a discursividade de Iracema (UPE), quando nos revela que: “A luta é um conjunto, é uma nação, é uma bandeira, é um hino, que move, move toda essa população brasileira!". Estar ocupando era se sentir parte do espaço público mais do que se sentia antes. Castro (2008) ainda defende que se dar conta desse pertencimento responsabiliza e integra:

Para o jovem, "sair de casa", no sentido de assumir-se como integrante da polis ou da nação, significa entender-se como "tendo a ver" com o estado de coisas ao seu redor e interpelado a responsabilizar-se por elas. Pertencimento e responsabilização imbricam-se e constituem aspectos subjetivos primordiais no processo de assumir-se como membro de uma sociedade, seja ela qual for (p. 253).

Diante disso, Euclides (UPE) faz uma importante reflexão quando mostra que o sujeito sozinho não consegue grandes transformações:

E quando Paulo Freire fala da Pedagogia do Otimismo que ele diz que é a burguesia, a classe, que...que...subjuga, divide pra oprimir! Ele fala disso, dividir o povo, se o povo não ta unido o povo não consegue, você não consegue, eu não consigo, mas se todo mundo se unir, se uma grande massa se unir, consegue!"’.

A participação nas ocupações promoveu alterações na forma de engajamento desses jovens, através da mudança de vida deles, do aprendizado, de um novo olhar e uma reconfiguração de atividades que dirigiam àquela mesma instituição de que já participavam. Alguns disseram já ter se vinculado a movimentos sociais e políticos, outros disseram que não suportavam política. Mas, no contexto das Ocupações, todos estavam ali tentando fazer a 
diferença ante a conjuntura vivida, buscando lidar com a diversidade de opiniões, se articulando para chamar atenção para suas requisições.

A participação política (...) envolve ações produzidas por um sujeito político com fins de afirmação dos posicionamentos individuais e/ou coletivos. Passa pela experienciação do convívio com as diferenças e inclui, também, a tomada de reflexões e atitudes na luta ou defesa de pautas coletivas. Trata, enfim, da reinvenção de si e dos espaços públicos (MENDONÇA, 2016, p. 160).

Nesse argumento, se percebe o que Aloísio (UAG) traz:

Então veja que tipo de sociedade tava se construindo ali. Ali eu tava junto com ateu, com protestante, gays, né? Negros, quilombolas, indígenas, então veja, pessoas é... espíritas, e estavam ali lutando com um bem comum, de todos, respeitando cada um, certo?! Então veja que importância que esse movimento teve, veja que a finalidade que se chegou, né?

Como também podemos destacar as mudanças subjetivas elencadas: "Eu passei mais em pensar sobre o que eu fazia, sobre os meus atos, passei mais a pensar sobre minha profissão." (Euclides, UPE). "Eu fiquei uma pessoa muito politizada, mas também me trouxe calmaria!" (Iracema, UPE).

Mas estar aqui com as pessoas que você sabia que estavam lutando por algo que era... de um compartilhar imenso, é, foi muito grandioso (...) me fez perceber que é aos poucos que a gente vai chegando e aos poucos a nossa voz vai ficando cada vez mais alta (Julieta, UPE).

Eu acho que a visão do humano, do respeito, (...) não porque é uma obrigação, mas porque eu também sou humano e eu tenho que me ver no outro, que meus olhos não são suficientes, eu tenho que me olhar pelo olhar do outro, eu acho que a ocupação foi a prática disso (...). (Gal, UAG).

Sendo assim, a ocupação é lembrada por eles evocando-se as palavras: "amor, carinho, família, gratidão, apreço, saudades, união, luta, resistência, grupo, coletivo, amizades, desafios, dificuldades, vagabundos, perdas, contra, conflitos, tensão, solidão, sopão, natal, força."

As Ocupações tiveram como um de seus desdobramentos a formação de distintos Coletivos. Estes se organizam e se articulam nas redes sociais, mantendo contato para o diálogo e serve como estratégia de ação e mobilização juvenil na Universidade. Isso facilita a interação e conecta de modo globalizado. Nos atuais movimentos, essa maneira de se juntar "são laboratórios de experimentações de novas formas de operar a política" (Gohn, 2014, p. 432). Assim também, há que se destacar a possibilidade de implementação ou mesmo a permanência de iniciativas estudantis para discutir, melhorar e organizar a estadia no ensino superior, através do DCE (Diretório Central dos Estudantes), uma entidade que representa discentes de uma Universidade, bem como o CA (Centro Acadêmico), entidade representativa Barbarói, Santa Cruz do Sul, n.53, p.<26-48>,jan./jun. 2019 
estudantes de um curso. Essas entidades já existiam nas instituições estudadas, mas foram fortalecidas e renovadas após o período de Ocupação, segundo afirmaram os participantes da pesquisa.

Findado o movimento de Ocupação, os jovens participantes se auto avaliam como engajados, mas de uma maneira um tanto diferente: alguns estão finalizando o curso ou iniciando a carreira profissional, se sentindo afastados e focados nas demandas dessa etapa da vida. Porém, ainda assim conseguem, através de um olhar crítico e de suas implicações em diálogos coletivos, perceber e exercer a política nas ruas, em casa, em suas atitudes e em seu dia-a-dia. Como afirma Iracema (UPE) “A gente sempre está em rua, em protesto, a gente sempre tá em redes sociais, divulgando o que tá se passando, tentando levar mais informações possíveis".

Aloízio (UAG) destaca uma mudança em seu comportamento junto as pessoas:

(...) hoje minha atuação pode se dizer que é mais na conversação com os colegas, com o que ta se passando, o que pode ser feito, escuto mais opiniões contrárias, antes era muito intolerante quando alguém falava mal do que eu achava ser certo, entre aspas, e hoje eu escuto mais, e é isso!

Nesse contexto, também se percebem ativos na construção da democracia e isso os torna responsáveis por suas escolhas, fazendo valer deveres e direitos, numa postura de escuta das opiniões divergentes e isso favorece a democracia.

Por outro lado, se mostraram descontentes com as circunstâncias em que o país se encontra, desaprovando o atual governo ${ }^{10}$. Perguntamos como eles se sentiam com a situação do Brasil. Eis alguns de seus posicionamentos:

Eu me vejo muito prejudicado. Não só eu, ne? Todo jovem. Acho que a gente se vê tanto em âmbito municipal, quanto estadual, quanto federal que é uma crescente desvalorização, um desrespeito pra o povo, pra os votos que a gente coloca nessa galera que se diz fazer política (Augusto, UPE).

Eu sinto o mesmo rolo compressor lá de antes da ocupação, se aproximando ou já passando por cima da gente mesmo, não é nem se aproximando, já passando e parece que todo dia é a mesma coisa, o mesmo rolo compressor passando por cima da gente (Jorge, UPE).

Tantas coisas aí... corrupção, escândalos, isso é bom, porque tá vindo à tona o que estava escondido há anos, se comparar dez anos atrás com hoje, evoluiu muito, então mostrar o que está ruim para o povo brasileiro, é bom. (Aloísio, UAG).

\footnotetext{
${ }^{10} \mathrm{O}$ atual Presidente Michel Temer tem mais de $70 \%$ de rejeição segundo pesquisas do IBOPE e o Datafolha, sendo um número ainda maior da desconfiança no presidente e com perceptual de cerca de $6 \%$ de aprovação, números que o faz ser avaliado como o pior chefe de Estado de todos os tempos do Brasil.

Disponível em: < http://www.ibopeinteligencia.com/noticias-e-pesquisas/77-dos-brasileiros-avaliamnegativamente-governo-temer/> Acesso em: 30/05/2018

Disponível em: < http://datafolha.folha.uol.com.br/opiniaopublica/2018/04/1965208-estavel-governo-temermantem-reprovacao-de-70-dos-brasileiros.shtml> Acesso em: 30/05/2018
}

Barbarói, Santa Cruz do Sul, n.53, p.<26-48>,jan./jun. 2019 
Segundo Gohn (2011), a historicidade e atualidade se fazem influência no arranjo de cada movimento, em seu processo de ser marcado e marcar a experiência em sociedade:

\begin{abstract}
$\mathrm{Na}$ realidade histórica, os movimentos sempre existiram, e cremos que sempre existirão. Isso porque representam forças sociais organizadas, aglutinam as pessoas não como força-tarefa de ordem numérica, mas como campo de atividades e experimentação social, e essas atividades são fontes geradoras de criatividade e inovações socioculturais. A experiência da qual são portadores não advém de forças congeladas do passado - embora este tenha importância crucial ao criar uma memória que, quando resgatada, dá sentido às lutas do presente. A experiência recria-se cotidianamente, na adversidade das situações que enfrentam (p. 336).
\end{abstract}

Nesse contexto, alguns enxergam no voto a possibilidade de mudanças e, na informação, a chave para se libertar da ignorância. É no cotidiano que isso pode ser modificado, é na união e na troca de ideias "é na conversa com os colegas", "é no diálogo", “escutando o diferente" (SIC). É difícil ouvir as opiniões divergentes, afirmam os jovens entrevistados, mas é um modo de se aproximar, de unir, de conseguir ter forças para reivindicar e ser visto como cidadãos em vida democrática.

\title{
Considerações
}

Os sentidos de participação política juvenil, no contexto dessa pesquisa, foram construídos associando-os às ações do cotidiano, investidas no cenário do movimento de Ocupação de duas Universidades públicas do interior do estado de Pernambuco. O pensar e o agir político expressaram-se na rotina estabelecida, nas atividades de formação política e conhecimento da realidade social em que os jovens estudantes estiveram inseridos, dentro dos muros da instituição ou fora deles, nas estratégias de transformação da sociedade em que vivem, em seus posicionamentos de resistência afirmados com seus parceiro de luta, bem como com aqueles que se opunham ao movimento, nos aprendizados do lidar com os dissensos.

Sendo uma experiência única para os jovens engajados no movimento, conforme enfatizaram em distintos momentos das entrevistas, os participantes reconhecem e afirmam impactos do movimento de Ocupação na Universidade, na comunidade, no estado, na nação e, principalmente, em si mesmos, que agora se veem e se afirmam como sujeitos políticos. Eles se consideram transformados e descobriram por meio do diálogo, da escuta e respeito diante de opiniões contrárias, através da empatia e da valorização frente à alteridade, que na união e na diferença eles se fizeram mais fortes para resistir e para lutar. Acreditam e defendem serem eles mesmos representantes de uma grande parcela de jovens e, de maneira organizada, reivindicaram direitos estudantis que beneficiassem a toda a comunidade acadêmica.

Barbarói, Santa Cruz do Sul, n.53, p.<26-48>,jan./jun. 2019 
Para eles, a democracia não se resume a um conceito, mas à diversidade de argumentos, à possibilidade de um governo ser para/com o povo e o povo lutar pelo seu governo. Foram dois meses morando em solo público, discutindo sobre assuntos pertinentes aos interesses sociais, econômicos e políticos do Brasil. Entre os estudantes envolvidos nesse movimento, poucos haviam experienciado, em sua grade curricular formal, disciplinas específicas para discutir conteúdos políticos. Foi através da estratégia encontrada pelos jovens de não terem as aulas regulares que conseguiram, de forma autônoma e inventiva, construir seu aprendizado, assim como se espera do universitário, buscando conhecimentos interdisciplinares e calcados em seus contextos de vida.

Não nos cabe nessa pesquisa julgar se erraram ou acertaram, se participaram bem ou mal, a construção de sentidos se dá na interlocução com os atores sociais, assim como garante Gohn: "a aprendizagem no interior de um movimento social, durante e depois de uma luta, são múltiplas, tanto para o grupo como para indivíduos isolados” (2011, p. 352). Para esses jovens, a experiência foi marcante a tal ponto que, de algumas posturas apáticas na política, passaram a perceber a importância da coletividade e a possibilidade de votar melhor, de atuarem como cidadãos conscientes e repensarem sobre as escolhas, sobre comportamentos e atitudes frente aos outros e com os outros. Em seus relatos destacavam a Ocupação como uma das melhores experiências da Universidade, ou mesmo de suas vidas, pela intensidade e representatividade que aquilo tinha na história dos movimentos estudantis e de sua própria trajetória.

Compreendendo, assim, as juventudes em sua pluralidade e sua singularidade em transpor barreiras para a construção social de sua época, afirmamos, com esta pesquisa, que o jovem atua diante da possibilidade de se ver criador de discussões e arranjos políticos participativos, contribuindo de modo geracional, social, comunitário e, assim, político. Em uma dimensão micro e macrossocial, visualiza no esforço conjunto a garantia dos direitos básicos já constituídos, porém, que demandam constante manutenção, mobilização e engajamento para estar assegurado. Desse modo, o jovem se sente pertencente a uma esfera pública que garante a historicidade, tradição e há um elemento novo, que pertence à invenção e compromisso das juventudes.

Sendo assim, o olhar crítico e desnaturalizador, tal como propõe o Construcionismo Social, sobre o movimento de Ocupação pode oferecer diversidade nos sentidos produzidos sobre a participação política juvenil. Através de ações cotidianas, da conversa e mobilização para a realização de protestos, passeatas, panfletagem, a busca autônoma e inventiva de uma 
formação política e cultural, os desdobramentos na construção ou fortalecimento de coletivos que descendem das ocupações e a reverberação dessa experiência na vida acadêmica, política, social e pessoal desses jovens indicam sentidos de uma participação política que se constrói e se fortalece, afinal, estes jovens estudantes puderam experienciarar a subjetivação política num deslocamento do olhar exclusivo de si e seus interesses, na direção do outro, do público, do coletivo.

\title{
YOUTH POLITICAL PARTICIPATION: MEANING PRODUCTION IN THE CONTEXT OF UNIVERSITY OCCUPATIONS
}

\begin{abstract}
The Occupation movements that occurred in the second semester of 2016, in the Brazilian educational scope, evidenced a scenario in which students are having problems in the next two months, inhabiting educational institutions, in tests of guidelines and in manifestos of positions contrary to the proposed amendment public constitutional law as a 241 (or 55) PEC. Given this adverse context and its manifestations of resistance, a research was conducted under an epistemological perspective of Social Constructionism and aimed to analyze the meanings of political participation built by young people who experienced the Occupation movement in Public Universities. To this end, 20 individual, semi-structured interviews were conducted, ten young students from the University of Pernambuco and another 10 from the Federal Rural University of Pernambuco, in the fields located in the city of Garanhuns - PE. The data were analyzed through discursive practices and production of meanings in daily life, which propose to analyze processes and modes of subjectivation, considering discursivities as language in action. As the results, understand as Occupations not reaching their main claims, but as entrepreneurial political formation activities, an interaction between occupants and relief with contrary measures of who is defended, promote experiences of political participation, made visible through dialogues and daily activities, critical positions and implications for movements that move in the same direction in other directions, promoting subjective political implications for those involved.
\end{abstract}

Key words: Political participation; occupation; youth.

\section{REFERÊNCIAS}

ALVIM, R.. Olhares sobre a juventude. Comunicações do ISER. Edição especial: Juventude, cultura e cidadania. Rio de Janeiro, ano 21, 2002.

ABRAMO, H. W. Condição Juvenil no Brasil Contemporâneo. In ABRAMO, H. W. ; BRANCO, P. P. M. (Orgs.) Retratos da Juventude Brasileira: análises de uma pesquisa nacional. Rio de Janeiro: Fundação Perseu Abramo, 2005.

BAQUERO, R. V. A. Empoderamento: Instrumento de Emancipação Social? - Uma Discussão Conceitual. Revista Debates, Porto Alegre. v. 6, n. 1, p.173-187, jan.-abr. 2012. Disponível em: < http://www.seer.ufrgs.br/debates/article/viewFile/26722/17099/> Acesso em: 01 mar. 2018. 
BECKER, P.; RAVELOSON, J. A. O que é Democracia? Friedrich-Ebert-Stiftung. Edição Portuguesa, Luanda-Angola, 2011. Disponível em: <http://library.fes.de/pdffiles/bueros/angola/08202.pdf> Acesso em: 04 mar. 2018.

CARRANO, P. A participação social e política de jovens no Brasil1: considerações sobre estudos recentes. O Social em Questão. Ano XV, n. 27. 2012. Disponível em: < http://osocialemquestao.ser.puc-rio.br/media/OSocial27 Carrano1.pdf $>$ Acesso em: 04 mai. 2018.

CASSAB, C. Contribuição à construção das categorias jovem e juventude: uma introdução. Locus: revista de história. Juiz de Fora. v. 17, n.02 p. 145-159, 2011. Disponível em: < http://www.ufjf.br/nugea/files/2010/09/Locus.pdf> Acesso em: 23 abr. 2018.

CASTRO, L. R de. Participação Política e Juventude: Do mal-estar à responsabilização frente ao destino comum. Revista de Sociologia e Política. Curitiba, Brasil. v. 16, n. 30, p. 253-268. 2008. Disponível em: <http://www.scielo.br/scielo.php?pid=S0104-

44782008000100015\&script=sci_abstract\&tlng=pt > acesso em: 06 mai. 2018.

CASTRO, L. R. de. Onde estão os (sujeitos) jovens nas teorias da juventude?. In COLAÇO, V de F. R.; GERMANO, I. M. P.; MARINHO, L. L. (Orgs.). Juventudes em movimento: experiências, redes e afetos. Fortaleza: Expressão Gráfica e Editora. 2019. p. 69-88.

CASTRO, L.; MATOS, A. O que é que a política tem a ver com a transformação de si? considerações sobre a acção política a partir da juventude. Análise Social. v. 44, n. 193, p. 793-823. 2009.

CORBUCCI, P. R. Evolução do Acesso de Jovens à Educação Superior no Brasil. Instituto de Pesquisa Econômica Aplicada - IPEA, Brasília, 2014. Disponível em: <https://www.econstor.eu/bitstream/10419/121649/1/797106340.pdf> Acesso em: 09 set. 2019.

CORROCHANO, M.C.; DOWBOR, M.; JARDIM, F.A.A. Juventudes e participação política no Brasil do século XXI: Quais horizontes? Laplage em Revista. Sorocaba. v.4, n.1, jan.abr., p.50-66. 2018. Disponível em:

<https://dialnet.unirioja.es/servlet/articulo?codigo=6275807> Acesso em: 09 set. 2019.

DAYRELL, J. A escola "faz" as Juventudes? Reflexões em torno da socialização juvenil.

Educ. Soc. Campinas, v. 28, n. 100 - Especial, p. 1105-1128. 2007. Disponível em:

<http://www.cedes.unicamp.br> Acesso em: 05 mai. 2018.

ESTEVES, L. C. G., \& ABRAMOVAY, M. (2007). Juventude, juventudes: pelos outros e por elas mesmas. In M. Abramovay, E. R. Andrade \& L. C. Esteves (Orgs.). Juventudes: outros olhares sobre a diversidade. Brasília: Ministério da Educação, Secretaria de Educação Continuada, Alfabetização e Diversidade; UNESCO, p. 21-56. Disponível em: $<$ http://participatorio.juventude.gov.br/jspui/bitstream/192/160/1/MECUNESCO_juventudeso utrosolharessobreadiversidade_2007.pdf > Acesso em:01 mai. 2018.

GERGEN, K. J. O Movimento do Construcionismo Social na Psicologia Moderna. R. Inter. Interdisc. Interthesis, Florianópolis, v.6, n.1, p. 299-325, jan./jul. 2009. Disponível em: 
<https://periodicos.ufsc.br/index.php/interthesis/article/view/10976> Acesso em: 19 abr. 2018.

GOHN, M. G. Abordagens teóricas no estudo dos movimentos sociais na América Latina. Caderno CRH, Salvador, v. 21, n. 54, p. 439-455, Set./Dez. 2008. Disponível em: <http://www.scielo.br/pdf/ccrh/v21n54/03> acesso em: 23 abr. 2018.

Movimentos sociais na contemporaneidade. Revista Brasileira de Educação, v. 16, n. 47, mai-ago. 2011. Disponível em: <http://www.scielo.br/pdf/rbedu/v16n47/v16n47a05.pdf> Acesso em: 01 mar. 2018.

A sociedade brasileira em Movimento: vozes das ruas e seus ecos políticos e sociais. Universidade Federal da Bahia Salvador, Brasil. Caderno CRH, v. 27, n. 71, jun-ago, p. 431441. 2014. Disponível em: <http://www.redalyc.org/html/3476/347632473013/> Acesso em: 23 abr. 2018.

MARQUES, R. M.; XIMENEZ, S. B.; UGINO, C. K. Governos Lula e Dilma em matéria de seguridade social e acesso à educação superior. Revista de Economia Política, v. 38, n. 3 (152), p. 526-547, jul-set. 2018. Disponível em: 〈http://www.rep.org.br/PDF/152-8.PDF> Acesso em: 09 set 2019.

MAYORGA, C; PINTO, G. Juventudes: a pluralização da experiência ou a invisibilidade das relações de poder. In MENEZES, J. de A.; COSTA, M. R.; ARAÚJO, T. C. dos S. de. (Orgs.). Coletânea de trabalhos apresentados no V Simpósio Internacional sobre a Juventude Brasileira (JUBRA). Recife: Editora Universitária da UFPE, 2013, p. 101-114.

MENDONÇA, É. de S. Entre políticas de adesão e políticas de transformação: construções e expressões de subjetivação política em jovens militantes. Tese de doutorado, 2016. Disponível em: <https://repositorio.ufpe.br/bitstream/123456789/18670/1/2016_Mendon\%C3\%A7a.pdf> Aceso em: 22 abr. 2018.

MENDONÇA, É de S.; PERES, F. M. de A. e.; BAPTISTA, E. A.“Já estou implicado até a alma!": modos, expressões e desafios de subjetivação política juvenil. In COLAÇO, V de F. R.; GERMANO, I. M. P.; MARINHO, L. L. (Orgs.). Juventudes em movimento: experiências, redes e afetos. Fortaleza: Expressão Gráfica e Editora. 2019. p. 440-459.

MENDONÇA, É. de S.; ANDRADE, D. B.; HOLANDA, CORREIO, C. M. B. Juventude (des)politizada? Ampliando perspectivas no olhar à participação política juvenil. Psicologia Política. v.16, n.35. São Paulo. jan./abr. 2016.

MENDONÇA, É. de S. Práticas discursivas sobre participação política juvenil: entre os prazeres, orgulho e sacrifícios. Dissertação de Mestrado. Programa de Pós-Graduação em Psicologia. Recife: Universidade Federal de Pernambuco. 2008.

MISCHE, A. De estudantes a cidadãos redes de jovens e participação política. Revista Brasileira de Educação, Mai/Jun/Jul/Ago 1997, n.5 Set/Out/Nov/Dez 1997, n.6. Disponível em:<https://edisciplinas.usp.br/pluginfile.php/42959/mod_resource/content/1/Semin\%C3\%A 1rio\%20Mische.pdf> acesso em: 21 abr. 2018. 
MOUFFE, C. Democracia, cidadania e a questão do pluralismo. Política \& Sociedade. n. 03. 2003. Disponível em:

<https://periodicos.ufsc.br/index.php/politica/article/viewFile/2015/1763> Acesso em: 04 mai. 2018.

Por um modelo agonístico de Democracia. Rev. Sociol. Polít., Curitiba, 25, p. 11-23, nov. 2005. Disponível em: < http://www.scielo.br/pdf/rsocp/n25/31108 > Acesso em: 04 mai. 2018.

PAIS, J. M. As múltiplas "caras" da cidadania. In CASTRO, Lucia; CORREA, Jane. (Orgs.) Juventude contemporânea: perspectivas nacionais e internacionais. Rio de janeiro: Nau; Faperj, 2005.

SILVA, F. C. A. Juventude na Mídia Brasileira: estereótipos e exclusão. Revista Anagrama - Revista Interdisciplinar da Graduação Ano 1 - Edição 4 - São Paulo, Junho/Agosto. 2008. Disponível em: < https://www.revistas.usp.br/anagrama/article/view/35327/38047> acesso em: 23 abr. 2018.

SPINK, MJ. Linguagem e produção de sentidos no cotidiano [online]. Rio de Janeiro: Centro Edelstein de Pesquisas Sociais, 2010. Disponível em: <http://books.scielo.org/id/w9q43/pdf/spink-9788579820465.pdf> Acesso em: 18 abr. 2018.

VIEIRA, B. Ativismo juvenil e políticas públicas: o caso do centro de referência da juventude de Belo Horizonte (MG). Belo Horizonte: Letramento. 2019.

VINUTO, J. A Amostragem em bola de neve na Pesquisa Qualitativa: Um debate em aberto. Temáticas, Campinas, v. 22, n.44, p. 203-220, ago/dez. 2014. Disponível em: <https://www.ifch.unicamp.br/ojs/index.php/tematicas/article/view/2144/1637> Acesso em: 19 abr. 2018.

Data de recebimento: $25 / 11 / 2018$

Data de aceite: 03/09/2019

\section{Sobre as autoras:}

Demyhellen Araújo Souza Aragão é Psicóloga, formada pela Universidade de Pernambuco (UPE), atuando na área de Avaliação Psicológica, Psicologia Organizacional e do Trabalho. Endereço Eletrônico: demy.souza31@gmail.com

Érika de Sousa Mendonça é Professora Adjunta do Curso de Psicologia da Universidade de Pernambuco. Professora Colaboradora do Mestrado Profissional em Culturas Africanas, da Diáspora e dos Povos Indígenas da Universidade de Pernambuco. Doutora em Psicologia pelo Programa de Pós-Graduação em Psicologia da Universidade Federal de Pernambuco, na linha de pesquisa de Processos Psicossociais, Poder e Práticas Coletivas (2012-2016); Mestre pelo mesmo programa no período de 2006 a 2008; Especialista em Intervenções em Psicologia Clínica, pela Universidade Católica de Pernambuco (2004-2005). Desenvolvimento de 
projetos de pesquisa na linha da Psicologia Política, problematizando a juventude, modos e processos de subjetivação, participação política e políticas públicas de juventude.. Endereço Eletrônico: erika.mendonca@upe.br

Kerollayne Cavalcante Gominho é Psicóloga, Pós-graduanda da Residência Multiprofissional em Atenção Hospitalar com ênfase em Gestão do Cuidado do Hospital Regional Dom Moura. Endereço Eletrônico: kerollayne.c.g@gmail.com

Nathalia Regina Rodrigues Rocha de Santana é Psicóloga, formada pela Universidade de Pernambuco (UPE), pós-graduanda em Neuropsicologia (UnyLeya), pesquisadora nas áreas de Psicologia Social, Psicologia da Juventude e Psicologia do Esporte. Endereço Eletrônico: nathalia050132@gmail.com 